\title{
Selection of wastewater treatment process based on the analytical hierarchy process and fuzzy analytical hierarchy process methods
}

\author{
${ }^{1 *}$ A. R. Karimi; ${ }^{1}$ N. Mehrdadi; ${ }^{2}$ S. J. Hashemian; ${ }^{1}$ G. R. Nabi Bidhendi; ${ }^{3}$ R. Tavakkoli Moghaddam \\ ${ }^{1}$ Faculty of the Environment, University of Tehran, Tehran, Iran \\ ${ }^{2}$ Institute of Water and Energy, Sharif University of Technology, Tehran, Iran \\ ${ }^{3}$ Department of Industrial Engineering, University of Tehran, Tehran, Iran
}

Received 30 June 2010; $\quad$ revised 19 November 2010; accepted 21 December 2010; available online 1 March 2011

\begin{abstract}
ABSTRAC T: This paper presents an application of the analytical hierarchy process and fuzzy analytical hierarchy process methods for selecting the best wastewater treatment process. The analytical hierarchy process is one of the best ways for deciding among the complex criteria structure in different levels, and the fuzzy analytical hierarchy process is a synthetic extension of the classical method when the fuzziness of the decision makers are considered. After reviewing aerobic treatment processes operated in Iran's industrial estates and determining the main criteria used for treatment process evaluation, they are arranged in a hierarchy structure. Selection of the best wastewater treatment process is a multi-criteria decision making problem. Conventional methods are inadequate for dealing with the imprecise or vague nature of linguistic assessment. To overcome this difficulty, the fuzzy analytical hierarchy process is proposed for dealing with the vagueness of decision makers' judgments. The alternatives consist of extended aeration, absorption bio-oxidation, integrated fixed-film activated sludge, sequencing batch reactor, aerated lagoon. Based on the general condition of industrial estate's wastewater treatment plants, technical/administrative, economic and environmental criteria and their sub-criteria are weighted and then criteria evaluated and priorities of alternatives have been done by analytical hierarchy process and fuzzy analytical hierarchy process methods by the use of triangular fuzzy numbers. Finally, selection of the best process and ranking of these five processes are carried out by these foregoing methods, and some sensitivity analyses are conducted to show the results' sensitiveness to the changes of the weights of the evaluation criteria.
\end{abstract}

Keywords: Aerobic process; Fuzzy sets; Linguistic variables; Multi-criteria decision-making

\section{INTRODUCTION}

Selection of an appropriate treatment process is an important issue before designing and implementing any wastewater treatment plant (WWTP). The multicriteria decision making (MCDM) techniques are generally enabled to structure the problem clearly and systematically. With this characteristic, the decision makers have the possibility to easily examine and scale the problem in accordance with their requirements (Isiklar and Buyukozkan, 2006). Integrating methods are very useful in MCDM problem solution (Tuzkaya and Gülsün, 2008). The analytical hierarchy process (AHP) is useful for handling multiple criteria and objectives in the decision making process. Particularly, the application of AHP enables the consideration of

*Corresponding Author Email: karimia@ut.ac.ir Tel.: +98 218892 1187; Fax: +98 2188937046 socio-cultural and environmental objectives that are recognized to be of the same importance as the economic objective in selecting the optimal wastewater treatment alternative (Ellis and Tang, 1991 and 1994). The AHP approach is a systematic analysis technique for MCDM and it facilitates a rigorous definition of priorities and preferences of the decision makers. It is used to determine the weights of different factors (Saaty, 1977, 1988; Cheng and Wang, 2004; Bandyopadhyay and Chattopadhyay, 2007). The conventional methods for process selection are inadequate for dealing with the imprecise or vague nature of linguistic assessment. To overcome this difficulty, fuzzy multi-criteria decision-making (MCDM) methods are proposed. By using the fuzzy AHP, uncertainty and vagueness from subjective perception and the experiences of the decision-maker can be effectively represented and 
reached to a more effective decision (Chien and Shih, 2007; Nouri et al., 2008; Hadji Hosseinlou and Sohrabi, 2009).

In a real-world situation, the evaluation data of the treatment process suitability for various subjective criteria and the weights of the criteria are usually expressed in linguistic terms. Thus, in order to resolve the ambiguity frequently arising in available information and to perform more justice to the essential fuzziness in human judgment and preference, the fuzzy set theory has been used to establish MCDM problems (Liang, 1999).

There are many studies in the literature that used the AHP and fuzzy AHP methods for different MCDM problems. The AHP method, which was first introduced by Saaty (1988), is an effective method for solving MCDM problems. It has been widely used for MCDM and applied to many practical problems successfully. The AHP approach is a systematic analysis technique for MCDM and it facilitates a rigorous definition of priorities and preferences of the decision makers (Saaty, 1977, 1990; Guangming, 2007). The AHP is also a powerful and flexible MCDM tool for dealing with complex problems where both qualitative and quantitative aspects need to be considered. The AHP helps the analysts to organize the critical aspects of a problem into a hierarchy rather like a family tree. This is a method for ranking decision alternatives and selecting the best one when the decision maker (DM) has multiple criteria (Taylor, 2009). The traditional AHP requires exact or crisp judgments. However, due to the complexity and uncertainty involved in real-world decision problems, the DM may be more reluctant to provide crisp judgments than fuzzy ones. Furthermore, even when they use the same words, individual judgments of events are invariably subjective and the interpretations attached to the same words may differ (Soner Kara and Onut, 2010; Zhao et al., 2011). This is why fuzzy numbers and fuzzy sets have been introduced to characterize linguistic variables used to represent the imprecise nature of human cognition when trying to translate people's opinions into spatial data. The preferences in AHP are essentially human judgments based on human perceptions, so fuzzy approaches allow for a more accurate description of the decision-making process (Chen et al., 2008). AHP can be applied for environmental / social objectives which are recognized to be as the same important as the economic objective in selecting the best wastewater treatment alternative (Guangming et al., 2007; Dikinya and Areola, 2010; Khezri et al., 2010). In a study, Dabaghian et al. (2008) use AHP approach which uses expert's knowledge for selection of the best wastewater treatment alternative for electroplating workshops. There is an extensive literature that addresses the situation where the comparison ratios are imprecise judgments (Leung and Chao, 2000). In most of the real-world problems, some of the decision data can be precisely assessed while others cannot. Humans are unsuccessful in making quantitative predictions, whereas they are comparatively efficient in qualitative forecasting (Kulak and Kahraman, 2005).

Essentially, the uncertainty in the preference judgments rises to uncertainty in the ranking of alternatives as well as difficulty in determining consistency of preferences (Leung and Chao, 2000). These applications are performed with many different perspectives and proposed methods for the fuzzy AHP.

The AHP is one of the best ways for deciding among the complex criteria structure in different levels. The fuzzy AHP is a synthetic extension of the classical AHP method when the fuzziness of the decision makers is considered. The fuzzy AHP technique can be viewed as an advanced analytical method developed from the traditional AHP. Despite the convenience of AHP in handling both quantitative and qualitative criteria of MCDM problems based on DM judgments, fuzziness and vagueness existing in many decision-making problems may contribute to the imprecise judgments of the DM in conventional AHP approaches (Bouyssou et al., 2000). A number of methods have been developed to handle the fuzzy AHP. The first study of this method was proposed by Van Laarhoven and Pedrycz (1983) who compared fuzzy ratios described by triangular fuzzy numbers. In other work a hybrid fuzzy-analytic network process and fuzzy-preference ranking organization method is utilized for the evaluation of environmental performances of suppliers (Tuzkaya et al., 2009). Anagnostopoulos et al. (2007) performed the fuzzy extension of AHP in order to evaluate the alternative wastewater treatment process with the use of economic, environmental and social criteria. The research works explained in this paper has been performed in Tehran in 2009. The study is organized as follows: Firstly, the alternatives and the criteria, which affect the treatment process selection, have been determined. Secondly, an overview of the 
AHP and FAHP methods are explained. Finally, the application of these methods for selecting the best aerobic wastewater treatment process based on the field studies in Iran's industrial estates is described. The related results of these two methods are discussed and compared.

\section{MATERIALS AND METHODS}

Aerobic Treatment Alternatives

To consider aerobic treatment processes and related efficiency in industrial estates, a field study is carried out. The data analysis and related questionnaires are used for determining the efficiency of processes. This paper considers five aerobic treatment processes, which are operating in Iran industrial estates. These are as follows: 1) extended aeration (EA), 2) absorption- biooxidation (AB), 3) integrated fixed-film activated sludge (IFAS), 4) sequencing batch reactor (SBR) and 5) aerated lagoon (AL).

\section{Comparing Criteria}

According to quantity diversity of industrial wastewater and local condition of effluent sources, it is impossible to use general criteria in treatment process selection. However, some points are available in process selection, which is applied for almost all kinds of industrial wastewater to achieve the prior treatment process. The general procedure for making process selection usually consists of the following steps:
- Decide on the criteria that are used to evaluate alternatives.

- Identify criteria that are important.

- Develop treatment alternatives.

- Evaluate alternatives and select the best one.

Comparing criteria have been issued on the basis of objectivity in industrial estates. There are many criteria that influence selection of the wastewater treatment process. However, some criteria are so important that they tend to dominate the decision. In this paper, the alternatives of wastewater treatment are evaluated with the use of three sets of criteria as illustrated in Table 1.

A group of the decision makers, who are wastewater treatment specialists, help us to finalize the criteria as described below:

1) Technical/Administrative Criteria analyzed into the next nine sub-criteria:

- Applicability: The applicability of a process is evaluated on the basis of past experience, data from full-scale plants, published data, and from pilot-plant studies. If new or unusual conditions are encountered, pilot-plant studies are essential (Metcalf and Eddy, 2003).

- Performance: Performance is usually measured in terms of effluent quality and its variability, which must be consistent with the effluent discharge requirements. Alternatives are evaluated according to the quality of the effluents, by the percentage

Table 1: Criteria for selection of the wastewater treatment process

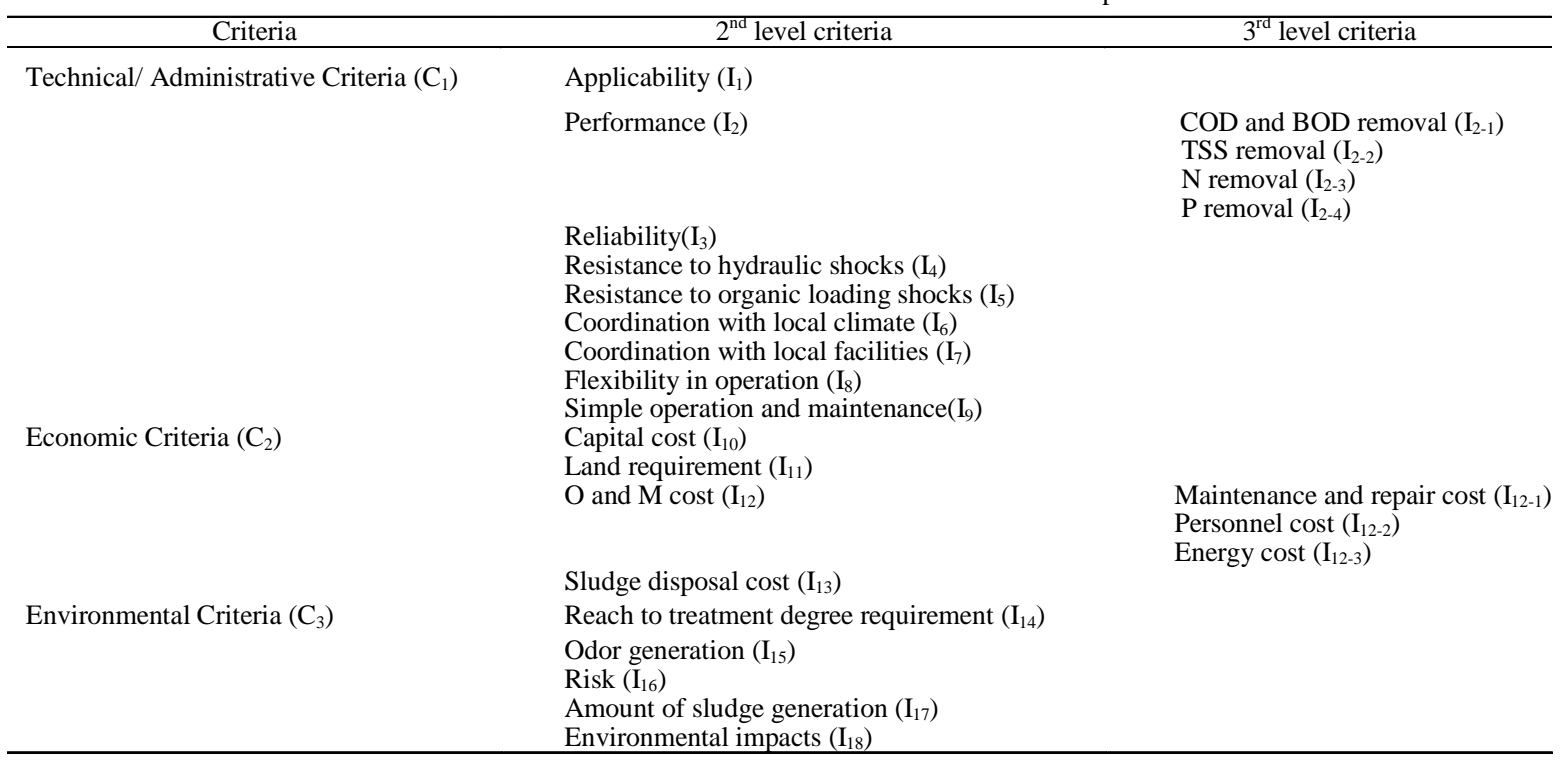


removal of chemical oxygen demand (COD), biochemical oxygen demand (BOD), total suspended solids (TSS), total nitrogen (TN) and total phosphorous (TP). - Reliability: In this sub-criterion the long-term reliability of the processes should be considered.

- Resistance to hydraulic shocks: The ability of processes regard to a wide range of flow rates have evaluated.

- Resistance to organic loading shocks: The characteristics of the influents wastewater affect the type of process. The ability of processes regard to high organic loading has evaluated.

- Coordination with local climate: Climatic constraints should be considered. Temperature affects the rate of reaction of the most biological processes. Warm temperatures may accelerate odor generation and also limit atmospheric dispersion.

- Coordination with local facilities: This sub-criterion is important in operation of the process. Some processes needed for the professional operations should be considered.

- Flexibility in operation: The ability of the process to work in a critical condition is evaluated.

- Simple operation and maintenance: Special operating or maintenance requirements should be considered.

2) Economic Criteria is analyzed into the next four sub-criteria:

- Capital cost: Usually includes costs for civil and mechanical works.

- Land requirement: Existing of sufficient space to accommodate not only the facilities currently but possible future expansion should be considered.

- Operation and Maintenance $(O$ and $M)$ cost: This sub-criterion consists of maintenance and repair cost, personnel cost and energy cost.The energy requirements and probable future energy cost must be known if the cost-effective treatment process is to be selected (Panjeshahi and Ataei, 2008).

- Sludge disposal cost: The amount of sludge production, treatment requirements and their related cost should be considered.

3) Environmental Criteria is analyzed into the next five sub-criteria:

- Reach to treatment degree requirement: The ability of processes is considered according to requirements of an effluent standard.

- Odor generation: Odors have been evaluated as the major concern of the public relative to the implementation of wastewater treatment facilities (Metcalf and Eddy, 2003). Odor control has become a major consideration in the wastewater treatment process selection, especially with respect to the public acceptance of the process.

- Risk: This sub-criterion is used for evaluation of safety for workers in different processes.

- Amount of sludge generation: Alternatives are evaluated taking into consideration the amount of the sludge produced by each treatment process (Anagnostopoulos et al., 2007).

- Environmental impacts: In this sub-criterion, general environmental impacts, such as amount of water evaporation, groundwater pollution and aerosol generation, are considered for evaluation of processes.

\section{Analytical Hierarchy Process (AHP)}

The AHP method is suitable for dealing with complex systems related to make a choice from several alternatives and which provides a comparison of the considered options. The AHP enables the DM to structure a complex problem in the form of a simple hierarchy and to evaluate a large number of quantitative and qualitative factors in a systematic manner with conflicting multiple criteria (Badri, 1999). In AHP, preferences between alternatives are determined by making pairwise comparisons, in which the DM examines two alternatives by considering one criterion and indicates a preference. These comparisons are made using a preference scale, which assigns numerical values to different levels of preference (Taha, 2003). The AHP helps the analysts to organize the critical aspects of a problem into a hierarchical structure similar to a family tree. By reducing complex decisions to a series of simple comparisons and rankings, then synthesizing the results, the AHP method not only helps the analysts to arrive at the best decision, but also provides a clear rationale for the choices made. The objective of using this method is to identify the preferred alternative and also determine a ranking of the alternatives when all the decision criteria are considered simultaneously (Saaty, 1988).

The use of AHP instead of another multi-criteria technique is due to the following reasons:

- Quantitative and qualitative criteria can be included in the decision making.

- A large quantity of criteria can be considered.

- A flexible hierarchy can be constructed according to the problem. 
The AHP is based on a hierarchical structuring of the elements that are involved in a decision problem. The evaluation of the hierarchy is based on pairwise comparisons. The DM compares two alternatives, $A_{i}$ and $A_{i}$, using a criterion and assigns a numerical value to their relative weight. When $n$ elements of a level are evaluated in pairs using an element of the higher level, an $n \times n$ comparison matrix is obtained. The pairwise comparisons matrix $A$ of alternatives with respect to criterion $K$ is as fallow:

\begin{tabular}{c|cccc}
$K$ & $A_{1}$ & $A_{2}$ & $\cdots$ & $A_{n}$ \\
\hline$A_{1}$ & 1 & $a_{12}$ & $\cdots$ & $a_{1 n}$ \\
$A_{2}$ & $1 / a_{12}$ & 1 & $\cdots$ & $a_{2 n}$ \\
$\vdots$ & $\vdots$ & $\vdots$ & $\vdots$ & $\vdots$ \\
$A_{n}$ & $1 / a_{1 n}$ & $1 / a_{2 n}$ & $\cdots$ & 1
\end{tabular}

The DM's judgment may not be consistent with one another, so AHP measures the inconsistency of judgments by calculating the consistency index CI of the matrix. The CI is in turn divided by the average random consistency index $\mathrm{RI}$ to obtain the consistency ratio CR. Table 2 presents the random average indices (RI) for various $n$. The RI index is a constant value for an $n \times n$ matrix, which has resulted from a computer simulation of matrices with random values from the 1-9 scale and for which. As a rule of thumb, a consistency ratio $(\mathrm{CR}=\mathrm{CI} / \mathrm{RI})$ value of $10 \%$ or less is acceptable; otherwise, the pairwise comparisons should be revised (Vargas, 1982).

The following steps for applying the AHP can be considered (Saaty, 1988, 1990, 2001).

1. Define the problem and determine its goal.
2. Structure the hierarchy from the top through the intermediate levels to the lowest level that usually contains the list of alternatives.

3. Construct a set of pair-wise comparison matrices for lower levels with one matrix for each element in the level immediately above by using the standard preference scale used for the AHP in a range of 1 to 9 scale as shown in Table 3 . The pairwise comparisons are done in terms of which element dominates the others.

4. There are $n(n-1)$ judgments required to develop the set of matrices in Step 3. Reciprocals are automatically assigned in each pair-wise comparison.

5. Hierarchical synthesis is now used to weight the eigenvectors by the weights of the criteria and the sum is taken over all weighted eigenvector entries corresponding to those in the next lower level of the hierarchy.

6. Having made all the pair-wise comparisons, the consistency is determined by using the eigenvalue, $\lambda_{\text {max }}$, in order to calculate the consistency index, CI.

7. Steps 3 to 6 are performed for all levels in the hierarchy. Professional commercial software (i.e., Expert Choice developed by Expert Choice, Inc. (Expert Choice, 2000) is available on the market, which simplifies the implementation of the AHP's steps and automates many of its computations.

\section{Fuzzy analytical hierarchy process (FAHP)}

In the fuzzy extension of AHP, the weights of the nine level fundamental scales of judgments are expressed via triangular fuzzy numbers (TFNs) in order to represent the relative importance among the hierarchy's criteria (Zhu et al., 1999). A TFN is fully

Table 2: The random average consistency indexes (RI) for various $n$

\begin{tabular}{rrrrrrrrrr}
\hline $\mathrm{N}$ & 1 & 2 & 3 & 4 & 5 & 6 & 7 & 8 \\
\hline $\mathrm{RI}$ & 0.00 & 0.00 & 0.58 & 0.9 & 1.12 & 1.24 & 1.32 & 1.41 \\
\hline
\end{tabular}

Source: Saaty (1977).

Table 3: Pair-wise comparison scale for AHP preferences

\begin{tabular}{lc}
\hline Verbal judgments of preferences & Numerical rating \\
\hline Equally preferred & 1 \\
Equally to moderately & 2 \\
Moderately preferred & 3 \\
Moderately to strongly & 4 \\
Strongly preferred & 5 \\
Strongly to very strongly & 6 \\
Very strongly preferred & 7 \\
Very strongly to extremely & 8 \\
Extremely preferred & 9 \\
\hline
\end{tabular}


characterized by a triple of real numbers $(l, m, u)$, where parameter $m$ gives the maximal grade of the membership function $\mu(x)$, and parameters $l$ and $u$ are the lower and upper bounds that limit the field of the possible evaluation (Zhu et al., 1999; Lamata, 2004).

$$
\mu(x)=\left\{\begin{array}{cc}
(x-l) /(m-l) & x \in[l, m] \\
(u-x) /(u-m) & x \in[m, u] \\
0 & \text { otherwise }
\end{array}\right.
$$

In this paper, priorities estimation is accomplished using the extent analysis method for estimating the synthetic degree value (Chang, 1996). In the original version of the method the final ranking of the alternatives is obtained by the possibility theory to measure the possibility of dominance of each alternative over the others (Klir, 1997; Enea and Piazza 2004). The possibility theory is strongly criticized as a defuzzification method, since it assigns quite often zero weights in the hierarchy criteria and sub-criteria (Enea and Piazza, 2004). To avoid questionable results and to reduce the loss of information that takes place during the defuzzification process, the overall priorities of the alternatives are obtained in fuzzy terms. Finally, their rankings are reached after normalization of the best non-fuzzy performance(BNP) value, which is estimated using the gravity centre method according to Equation 2 (Hsieh et al. 2004).

$$
B N P_{i}=\left(l_{1}+m_{1}+u_{1}\right) / 3
$$

This regards to the quantitative criteria priorities of the alternatives from pairwise comparisons derived using the ratio of their performance considering the examined criterion. For example, for two alternatives $A_{i}$ and $A_{j}$ if it is considered that their performance under a specific quantitative criterion is $w_{i}=\left(l_{i}, m_{i}\right.$, $\left.u_{i}\right)$ and $w_{j}=\left(l_{j}, m_{j}, u_{j}\right)$, respectively. Then the measure of their relative importance is expressed as $a_{i j}=w_{i} /$ $w_{j}=\left(l_{i} / u_{j}, m_{i} / m_{j}, u_{i} / l_{j}\right)$. Priorities vectors $S_{i}$ (i.e., synthetic degree value) are calculated by:

$$
S_{i}=\left\{\begin{array}{c}
S_{l i}=\min \left[\left(\prod_{j=1}^{n} a_{i j}\right)^{1 / n}\right] / \sum_{k=1}^{n}\left[\left(\prod_{j=1}^{n} a_{k j}\right)^{1 / n}\right] \\
S_{m i}=\left[\left(\prod_{j=1}^{n} m_{i j}\right)^{1 / n}\right] / \sum_{k=1}^{n}\left[\left(\prod_{j=1}^{n} m_{k j}\right)^{1 / n}\right] \\
S_{u i}=\max \left[\left(\prod_{j=1}^{n} a_{i j}\right)^{1 / n}\right] / \sum_{k=1}^{n}\left[\left(\prod_{j=1}^{n} a_{k j}\right)^{1 / n}\right]
\end{array}\right.
$$

Subject to:

$$
a_{k j} \in\left[l_{k j}, u_{k j}\right], \forall j>k ; a_{k j}=l / a_{k j}, \forall j<k ; a_{j j}=1
$$

\section{RESULTS AND DISCUSSION}

There are many criteria that influence the treatment process selection. In this study, following three criteria and their sub-criteria are taken into consideration.

1)Technical/administrative criteria, such as applicability, performance, reliability, resistance to hydraulic shocks, resistance to organic loading shocks, coordination with local climate, coordination with local facility, flexibility in operation, and simple operation and maintenance. 2)Economic criteria, such as capital cost, land requirement, operation and maintenance cost and sludge disposal cost.

3) Environmental criteria, such as reaching to treatment degree requirement, odor generation, risk and environmental impacts.

According to the AHP methodology, the second level criteria are evaluated via pairwise comparisons with respect to the overall goal (i.e., selection of the best treatment process), while the third and fourth level criteria are evaluated for their relative importance to the criterion or sub-criterion they belong. Finally, the alternatives are compared according to their performance in each selection criteria using scales for the quantitative parameters, and AHP scale of weights for the qualitative criteria. Five treatment alternatives are studied including extended aeration, absorption bio-oxidation (A/B), integrated fixed-film activated sludge (IFAS), sequencing batch reactor (SBR), aerated lagoon. Fig. 1 shows the hierarchy decision model that has five levels. The first level is goal showing the best wastewater treatment alternative, which has the maximum general profits. Three main criteria (i.e., technical/administrative, economic, and environmental) are located in the second level. Indices and their sub indices of each main criterion are in the third and fourth levels, and the last level is treatment alternatives.

\section{Application with the AHP method}

The AHP approach is a systematic analysis technique for MCDM that facilitates a rigorous 


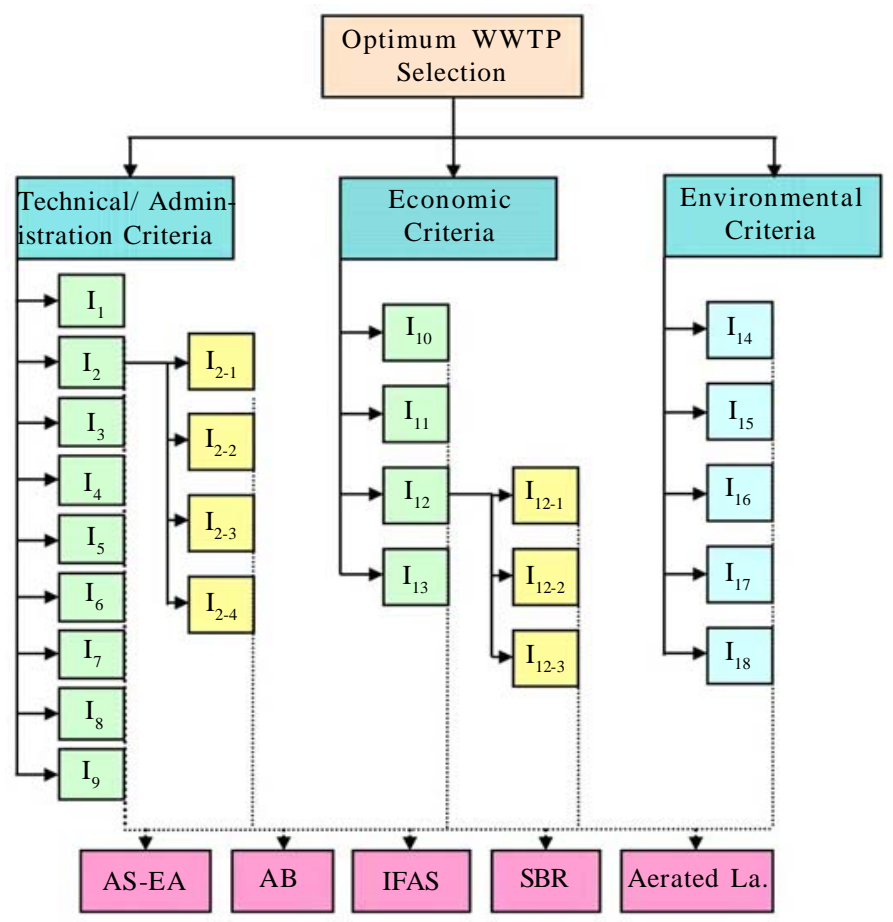

Fig. 1: Hierarchy decision model used in aerobic WWT process selection

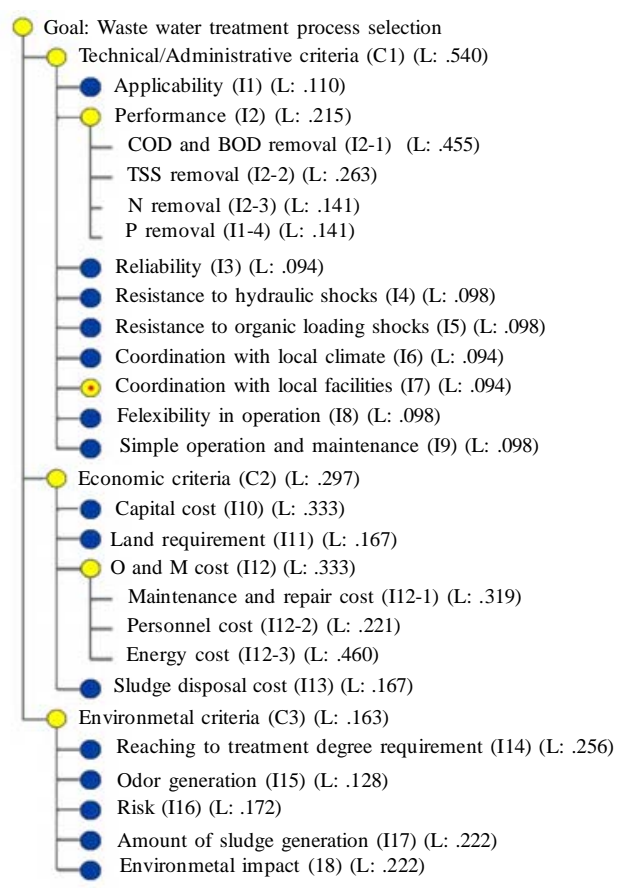

Fig. 2: Relative weights of criteria and sub-criteria in aerobic WWT process selection 
definition of priorities and preferences of the decision makers (Saaty, 1977, 1988). It has been used to determine the weights of different factors in this study. It allows group decision making, where group members can use their experience, values and knowledge to break down a problem into a hierarchy and solve it by the AHP steps. Brainstorming and sharing ideas and insights often lead to a more complete representation and understanding of the issues (Expert Choice, 2000).

Fig. 2 shows the relative weights of criteria and sub-criteria which are considered in aerobic wastewater treatment process selection, based on WWTP conditions that are in operation in Iran's industrial estates.
To evaluation of aerobic treatment processes, pairwise comparison matrices are created for each criteria and sub-criteria. After obtaining the satisfy consistency ratio of each matrix, relative weights of each criteria are calculated for different alternatives. The ranking order of the alternatives with respect to each main criterion and respect to overall goal (best aerobic treatment process) are illustrated in Figs. 3 to 6, respectively.

The ranking order of the alternatives in AHP method is IFAS $>$ Extended Aeration $>$ Aerated Lagoon $>$ SBR $>$ A/B. The sensitivity analysis can show the effect of input parameters change on the results. This analysis for the criteria level shows that the ranking order of alternatives remains
Extended Aeration

$\mathrm{AB}$

IFAS

SBR

Aerated Lagoon

SBR

Aerated Lagoon
AB

IFAS

Extended Aeration
Overall Inconsistency $=0.01$

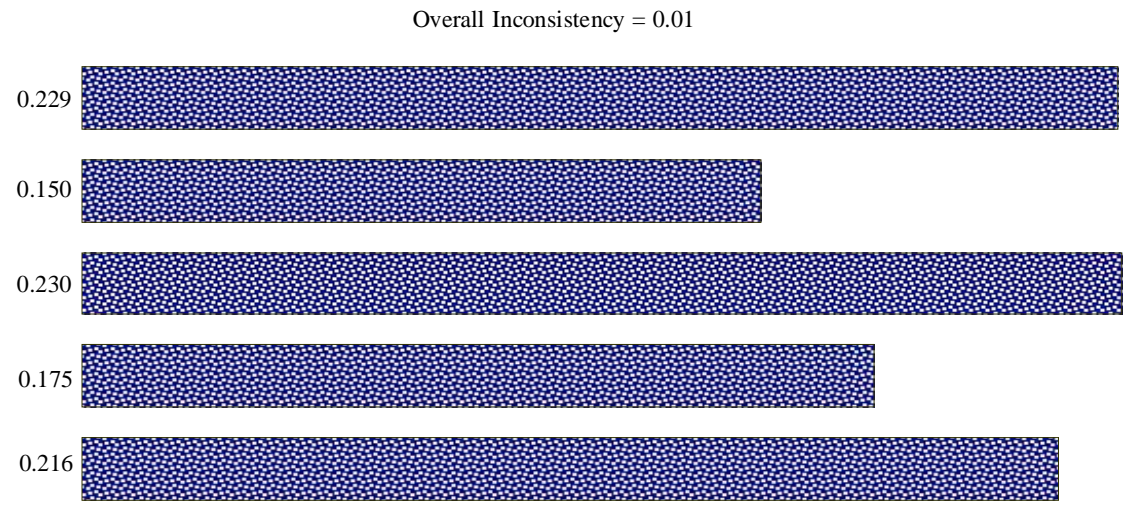

Fig. 3: Synthesis with respect to technical/administrative criteria $\left(\mathrm{C}_{1}\right)$
0.186

0.130

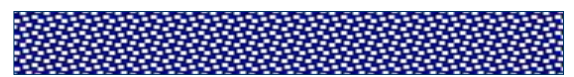

0.228

0.212

0.244

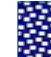

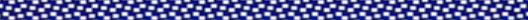

Overall Inconsistency $=0.01$
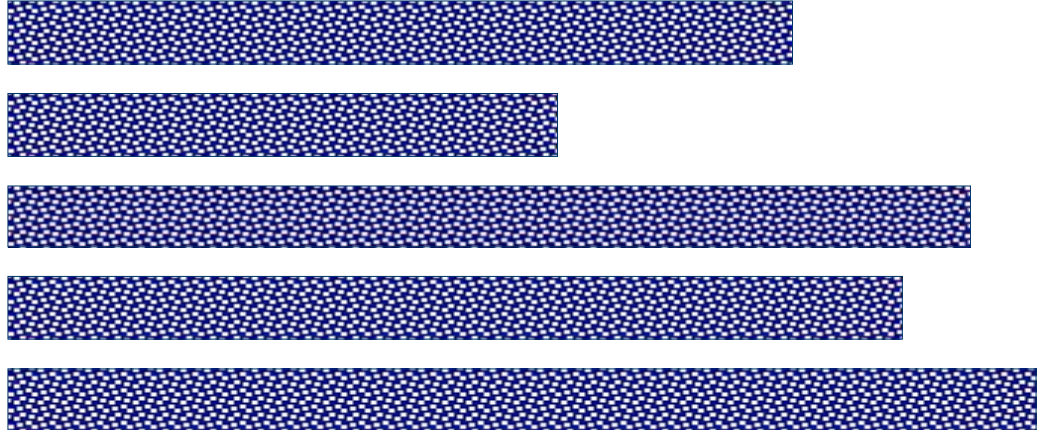

Fig. 4: Synthesis with respect to economic criteria $\left(\mathrm{C}_{2}\right)$ 
constant with changing the value of main three criteria.

Application with the fuzzy AHP method

In this section, the fuzzy AHP method is proposed for the same problem of aerobic treatment process selection. The Chang's extent analysis on the fuzzy AHP depends on the degree of possibilities of each criterion. According to the experts' judgments the corresponding triangular fuzzy values for the linguistic variables are placed and for a particular level on the hierarchy the pairwise comparison matrix is constructed. Sub totals are calculated for each row of the matrix and new $(l, m, u)$ set is obtained, then in order to find the overall triangular fuzzy values for each criterion, $l_{i} / \sum l_{i}, m_{i} / \sum m_{i}, u_{i} / \sum u_{i}$ values are found and used as the latest $M_{i}\left(l_{i}, m_{i}, u_{i}\right)$ set for criterion $M_{i}$ in

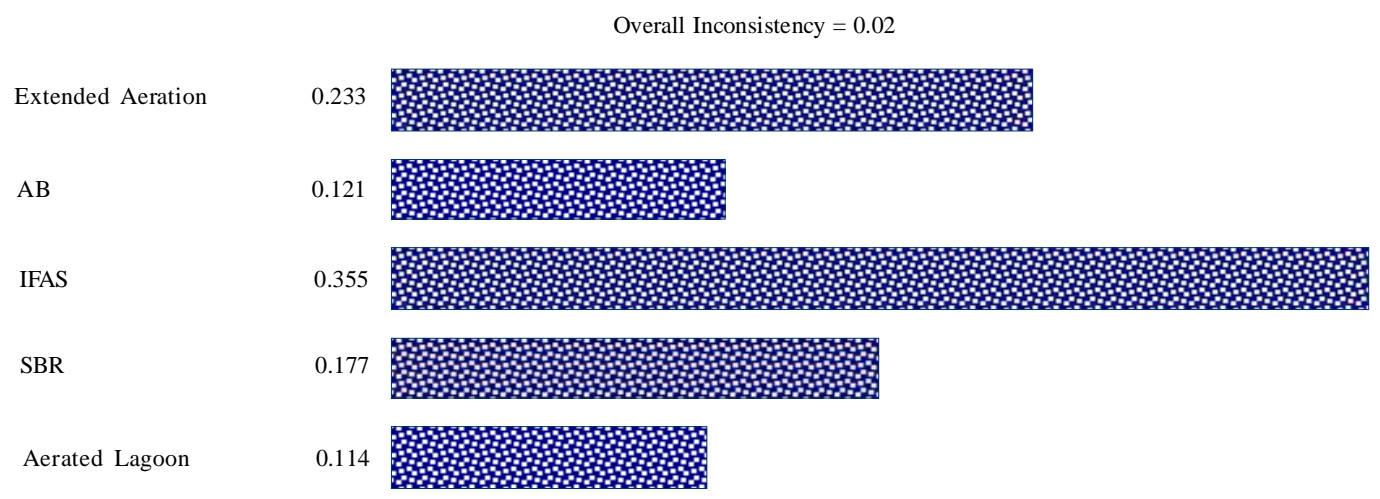

Fig. 5: Synthesis with respect to environmental criteria $\left(C_{3}\right)$

Overall Inconsistency $=0.02$

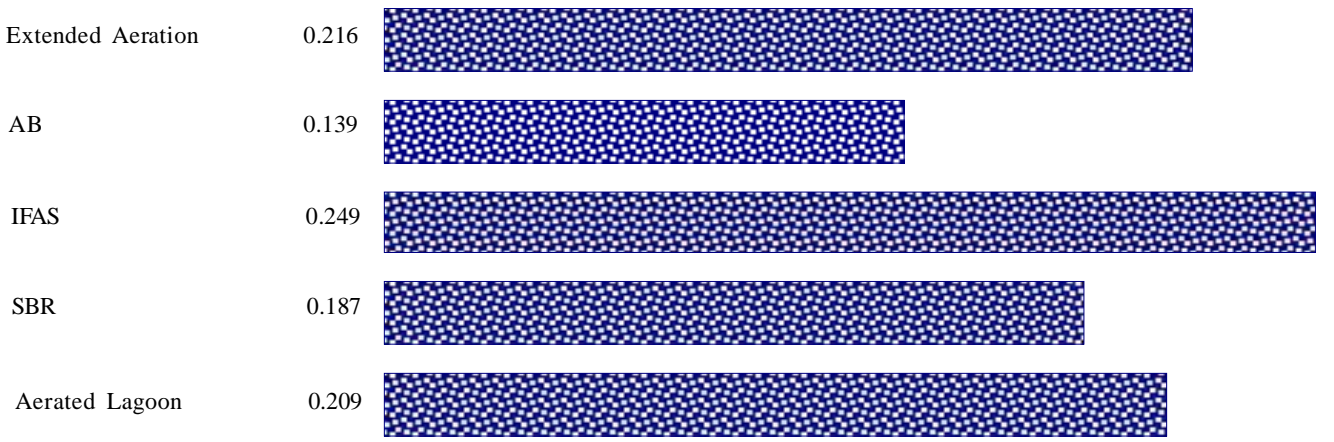

Fig. 6: Synthesis with respect to wastewater treatment process selection

Table 4: Fuzzy judgment scores in the fuzzy AHP

\begin{tabular}{ll}
\hline Uncertain judgment & Fuzzy score \\
\hline About equal & $(0.5,1,2)$ \\
About $x$ times more important ${ }^{\mathrm{a}}$ & $(x-1, x, x+1)$ \\
About $\mathrm{x}$ times less important & $(1 /(x+1), 1 / x, 1 /(x-1))$ \\
Between $y$ and $z$ times more important ${ }^{\mathrm{b}}$ & $(y,(y+z) / 2, z)$ \\
Between $y$ and $z$ times less important & $(1 / z, 2 /(y+z), 1 / y)$ \\
\hline a: $x=2,3, \ldots, 9 . \quad$ b: $y, z=1,2, \ldots, 9, y<z$ &
\end{tabular}


A. R. Karimi et al.

Table 5: Second, third and four level criteria priorities estimation

\begin{tabular}{|c|c|c|c|c|c|c|}
\hline \multirow{2}{*}{ 2nd Level Criteria } & \multicolumn{3}{|c|}{ Normalized eigenvectors } & \multicolumn{3}{|c|}{ Composite relative priorities } \\
\hline & $l$ & $m$ & $u$ & $l$ & $m$ & $u$ \\
\hline Technical/ Administrative Criteria (C1) & 0.459 & 0.612 & 0.765 & 0.459 & 0.612 & 0.765 \\
\hline Economic Criteria (C2) & 0.172 & 0.255 & 0.344 & 0.172 & 0.255 & 0.344 \\
\hline Environmental Criteria (C3) & 0.117 & 0.134 & 0.178 & 0.117 & 0.134 & 0.178 \\
\hline & \multicolumn{3}{|c|}{ Normalized eigenvectors } & \multicolumn{3}{|c|}{ Composite relative priorities } \\
\hline 3rd Level Criterıa & $l$ & $m$ & $u$ & $l$ & $m$ & $u$ \\
\hline Applicability $\left(\mathrm{I}_{1}\right)$ & 0.071 & 0.112 & 0.179 & 0.033 & 0.069 & 0.137 \\
\hline Performance $\left(I_{2}\right)$ & 0.135 & 0.207 & 0.28 & 0.062 & 0.127 & 0.214 \\
\hline Reliability $\left(\mathrm{I}_{3}\right)$ & 0.06 & 0.081 & 0.118 & 0.028 & 0.05 & 0.090 \\
\hline Resistance to hydraulic shocks $\left(\mathrm{I}_{4}\right)$ & 0.071 & 0.112 & 0.179 & 0.033 & 0.069 & 0.137 \\
\hline Resistance to organic loading shocks $\left(\mathrm{I}_{5}\right)$ & 0.06 & 0.101 & 0.179 & 0.028 & 0.062 & 0.137 \\
\hline Coordination with local climate $\left(\mathrm{I}_{6}\right)$ & 0.054 & 0.079 & 0.129 & 0.025 & 0.048 & 0.099 \\
\hline Coordination with local facilities $\left(\mathrm{I}_{7}\right)$ & 0.054 & 0.083 & 0.14 & 0.025 & 0.051 & 0.107 \\
\hline Flexibility in operation $\left(\mathrm{I}_{8}\right)$ & 0.071 & 0.112 & 0.179 & 0.033 & 0.069 & 0.137 \\
\hline Simple operation and maintenance $\left(\mathrm{I}_{9}\right)$ & 0.071 & 0.112 & 0.179 & 0.033 & 0.069 & 0.137 \\
\hline Capital cost $\left(\mathrm{I}_{10}\right)$ & 0.219 & 0.313 & 0.438 & 0.038 & 0.08 & 0.151 \\
\hline Land requirement $\left(\mathrm{I}_{11}\right)$ & 0.188 & 0.24 & 0.313 & 0.032 & 0.061 & 0.108 \\
\hline $\mathrm{O} \& \mathrm{M}$ cost $\left(\mathrm{I}_{12}\right)$ & 0.188 & 0.261 & 0.375 & 0.032 & 0.067 & 0.129 \\
\hline Sludge disposal cost $\left(\mathrm{I}_{13}\right)$ & 0.156 & 0.188 & 0.25 & 0.027 & 0.048 & 0.086 \\
\hline Reaching to treatment degree requirement $\left(\mathrm{I}_{14}\right)$ & 0.151 & 0.201 & 0.264 & 0.018 & 0.027 & 0.047 \\
\hline Odor generation $\left(\mathrm{I}_{15}\right)$ & 0.113 & 0.139 & 0.188 & 0.013 & 0.019 & 0.033 \\
\hline Risk $\left(\mathrm{I}_{16}\right)$ & 0.132 & 0.17 & 0.226 & 0.015 & 0.023 & 0.04 \\
\hline Amount of sludge generation $\left(\mathrm{I}_{17}\right)$ & 0.17 & 0.245 & 0.339 & 0.02 & 0.033 & 0.06 \\
\hline Environmental impacts (18) & 0.17 & 0.245 & 0.339 & 0.02 & 0.033 & 0.06 \\
\hline \multirow{2}{*}{ 4th Level Criteria } & \multicolumn{3}{|c|}{ Normalized eigenvectors } & \multicolumn{3}{|c|}{ Composite relative priorities } \\
\hline & $l$ & $m$ & $u$ & $l$ & $m$ & $u$ \\
\hline COD and BOD removal $\left(\mathrm{I}_{2-1}\right)$ & 0.229 & 0.371 & 0.514 & 0.014 & 0.047 & 0.011 \\
\hline TSS removal $\left(\mathrm{I}_{2-2}\right)$ & 0.2 & 0.267 & 0.343 & 0.012 & 0.034 & 0.073 \\
\hline $\mathrm{N}$ removal $\left(\mathrm{I}_{2-3}\right)$ & 0.133 & 0.181 & 0.286 & 0.008 & 0.023 & 0.061 \\
\hline$P$ removal $\left(\mathrm{I}_{2-4}\right)$ & 0.133 & 0.181 & 0.286 & 0.008 & 0.023 & 0.061 \\
\hline Maintenance and repair cost $\left(\mathrm{I}_{12-1}\right)$ & 0.263 & 0.333 & 0.421 & 0.008 & 0.022 & 0.054 \\
\hline Personnel cost $\left(\mathrm{I}_{12-2}\right)$ & 0.21 & 0.264 & 0.315 & 0.007 & 0.018 & 0.041 \\
\hline Energy cost $\left(\mathrm{I}_{12-3}\right)$ & 0.315 & 0.421 & 0.526 & 0.01 & 0.028 & 0.068 \\
\hline
\end{tabular}

Table 6: Synthetic degree values for the alternatives aerobic treatment processes

\begin{tabular}{|c|c|c|c|c|c|c|}
\hline \multirow[t]{3}{*}{ Treatment Process } & \multicolumn{6}{|c|}{ Extended aeration } \\
\hline & \multicolumn{3}{|c|}{ Normalized Eigenvectors } & \multicolumn{3}{|c|}{ Composite Relative Priorities } \\
\hline & $l$ & $m$ & $u$ & $l$ & $m$ & $u$ \\
\hline Applicability $\left(\mathrm{I}_{1}\right)$ & 0.158 & 0.248 & 0.407 & 0.005 & 0.017 & 0.056 \\
\hline COD and BOD removal $\left(\mathrm{I}_{2-1}\right)$ & 0.145 & 0.22 & 0.306 & 0.002 & 0.010 & 0.003 \\
\hline TSS removal $\left(\mathrm{I}_{2-2}\right)$ & 0.129 & 0.218 & 0.308 & 0.002 & 0.007 & 0.022 \\
\hline $\mathrm{N}$ removal $\left(\mathrm{I}_{2-3}\right)$ & 0.055 & 0.21 & 0.397 & 0.000 & 0.005 & 0.024 \\
\hline $\mathrm{P}$ removal $\left(\mathrm{I}_{2-4}\right)$ & 0.026 & 0.213 & 0.545 & 0.000 & 0.005 & 0.033 \\
\hline Reliability $\left(\mathrm{I}_{3}\right)$ & 0.124 & 0.204 & 0.327 & 0.003 & 0.010 & 0.029 \\
\hline Resistance to hydraulic shocks $\left(\mathrm{I}_{4}\right)$ & 0.104 & 0.216 & 0.395 & 0.003 & 0.015 & 0.054 \\
\hline Resistance to organic loading shocks $\left(\mathrm{I}_{5}\right)$ & 0.144 & 0.202 & 0.307 & 0.004 & 0.013 & 0.042 \\
\hline Coordination with local climate $\left(\mathrm{I}_{6}\right)$ & 0.099 & 0.209 & 0.344 & 0.002 & 0.010 & 0.034 \\
\hline Coordination with local facilities $\left(\mathrm{I}_{7}\right)$ & 0.111 & 0.196 & 0.326 & 0.003 & 0.010 & 0.035 \\
\hline Flexibility in operation $\left(\mathrm{I}_{8}\right)$ & 0.11 & 0.187 & 0.311 & 0.004 & 0.013 & 0.043 \\
\hline Simple operation and maintenance $\left(\mathrm{I}_{9}\right)$ & 0.103 & 0.216 & 0.364 & 0.003 & 0.015 & 0.050 \\
\hline Capital cost $\left(\mathrm{I}_{10}\right)$ & 0.099 & 0.209 & 0.344 & 0.004 & 0.017 & 0.052 \\
\hline Land requirement $\left(\mathrm{I}_{11}\right)$ & 0.123 & 0.23 & 0.328 & 0.004 & 0.014 & 0.035 \\
\hline Maintenance and repair cost $\left(\mathrm{I}_{12-1}\right)$ & 0.093 & 0.186 & 0.352 & 0.001 & 0.004 & 0.019 \\
\hline Personnel cost $\left(\mathrm{I}_{12-2}\right)$ & 0.111 & 0.205 & 0.349 & 0.001 & 0.004 & 0.014 \\
\hline Energy cost $\left(\mathrm{I}_{12-3}\right)$ & 0.088 & 0.191 & 0.348 & 0.001 & 0.005 & 0.024 \\
\hline Sludge disposal cost $\left(\mathrm{I}_{13}\right)$ & 0.101 & 0.188 & 0.314 & 0.003 & 0.009 & 0.027 \\
\hline Reaching to treatment degree requirement $\left(\mathrm{I}_{14}\right)$ & 0.148 & 0.207 & 0.312 & 0.003 & 0.006 & 0.015 \\
\hline Odor generation $\left(\mathrm{I}_{15}\right)$ & 0.105 & 0.213 & 0.382 & 0.001 & 0.004 & 0.013 \\
\hline Risk $\left(\mathrm{I}_{16}\right)$ & 0.129 & 0.222 & 0.334 & 0.002 & 0.005 & 0.013 \\
\hline Amount of sludge generation $\left(\mathrm{I}_{17}\right)$ & 0.124 & 0.214 & 0.329 & 0.002 & 0.007 & 0.020 \\
\hline Environmental impacts (18) & 0.104 & 0.217 & 0.371 & 0.002 & 0.007 & 0.022 \\
\hline Final Priorities & & & & 0.056 & 0.212 & 0.680 \\
\hline
\end{tabular}


Int. J. Environ. Sci. Tech., 8 (2), 267-280, Spring 2011

Table 6: Synthetic degree values for the alternatives aerobic treatment processes (continued)

\begin{tabular}{|c|c|c|c|c|c|c|c|c|c|c|c|c|}
\hline \multirow{3}{*}{$\begin{array}{l}\text { Treatment } \\
\text { Proc. } \\
\text { Criteria }\end{array}$} & \multicolumn{6}{|c|}{$\mathrm{A} / \mathrm{B}$} & \multicolumn{6}{|c|}{ IFAS } \\
\hline & \multicolumn{3}{|c|}{ Normalized eigenvectors } & \multicolumn{3}{|c|}{ Composite relative priorities } & \multicolumn{3}{|c|}{ Normalized eigenvectors } & \multicolumn{3}{|c|}{ Composite relative priorities } \\
\hline & $l$ & $m$ & $u$ & $l$ & $m$ & $u$ & $l$ & $m$ & $u$ & $l$ & $m$ & $u$ \\
\hline$\left(\mathrm{I}_{2-1}\right)$ & 0.142 & 0.195 & 0.281 & 0.002 & 0.009 & 0.003 & 0.161 & 0.244 & 0.314 & 0.002 & 0.011 & 0.003 \\
\hline$\left(I_{2-2}\right)$ & 0.099 & 0.198 & 0.288 & 0.001 & 0.007 & 0.021 & 0.129 & 0.218 & 0.308 & 0.002 & 0.007 & 0.022 \\
\hline$\left(I_{3}\right)$ & 0.121 & 0.183 & 0.298 & 0.003 & 0.009 & 0.027 & 0.124 & 0.204 & 0.327 & 0.003 & 0.010 & 0.029 \\
\hline$\left(\mathrm{I}_{4}\right)$ & 0.101 & 0.194 & 0.36 & 0.003 & 0.013 & 0.049 & 0.085 & 0.172 & 0.344 & 0.003 & 0.012 & 0.047 \\
\hline$\left(\mathrm{I}_{5}\right)$ & 0.11 & 0.183 & 0.287 & 0.003 & 0.011 & 0.039 & 0.147 & 0.228 & 0.334 & 0.004 & 0.014 & 0.046 \\
\hline$\left(\mathrm{I}_{6}\right)$ & 0.099 & 0.209 & 0.344 & 0.002 & 0.010 & 0.034 & 0.099 & 0.209 & 0.344 & 0.002 & 0.010 & 0.034 \\
\hline$\left(\mathrm{I}_{7}\right)$ & 0.093 & 0.174 & 0.312 & 0.002 & 0.009 & 0.033 & 0.111 & 0.196 & 0.326 & 0.003 & 0.010 & 0.035 \\
\hline$\left(\mathrm{I}_{12-1}\right)$ & 0.111 & 0.21 & 0.368 & 0.001 & 0.005 & 0.020 & 0.093 & 0.186 & 0.352 & 0.001 & 0.004 & 0.019 \\
\hline$\left(\mathrm{I}_{12-2}\right)$ & 0.093 & 0.181 & 0.334 & 0.001 & 0.003 & 0.014 & 0.111 & 0.205 & 0.349 & 0.001 & 0.004 & 0.014 \\
\hline$\left(\mathrm{I}_{12-3}\right)$ & 0.088 & 0.191 & 0.348 & 0.001 & 0.005 & 0.024 & 0.103 & 0.191 & 0.332 & 0.001 & 0.005 & 0.023 \\
\hline$\left(\mathrm{I}_{13}\right)$ & 0.084 & 0.166 & 0.3 & 0.002 & 0.008 & 0.026 & 0.103 & 0.21 & 0.345 & 0.003 & 0.010 & 0.030 \\
\hline$\left(\mathrm{I}_{14}\right)$ & 0.113 & 0.188 & 0.292 & 0.002 & 0.005 & 0.014 & 0.151 & 0.233 & 0.34 & 0.003 & 0.006 & 0.016 \\
\hline$\left(\mathrm{I}_{15}\right)$ & 0.102 & 0.191 & 0.348 & 0.001 & 0.004 & 0.011 & 0.14 & 0.265 & 0.445 & 0.002 & 0.005 & 0.015 \\
\hline$\left(\mathrm{I}_{16}\right)$ & 0.099 & 0.201 & 0.312 & 0.001 & 0.005 & 0.012 & 0.129 & 0.222 & 0.334 & 0.002 & 0.005 & 0.013 \\
\hline$\left(\mathrm{I}_{17}\right)$ & 0.077 & 0.154 & 0.268 & 0.002 & 0.005 & 0.016 & 0.126 & 0.24 & 0.358 & 0.003 & 0.008 & 0.021 \\
\hline (18) & 0.087 & 0.195 & 0.355 & 0.002 & 0.006 & 0.021 & 0.137 & 0.239 & 0.397 & 0.003 & 0.008 & 0.024 \\
\hline \multicolumn{4}{|c|}{ Final Priorities } & 0.048 & 0.187 & 0.630 & & & & 0.058 & 0.218 & 0.690 \\
\hline $\begin{array}{c}\text { Treatment } \\
\text { Proc. }\end{array}$ & \multicolumn{3}{|c|}{ Normalized eigenvectors } & \multicolumn{3}{|c|}{ Composite relative priorities } & \multicolumn{3}{|c|}{ Normalized eigenvectors } & \multicolumn{3}{|c|}{ Composite relative priorities } \\
\hline$\left(I_{2-2}\right)$ & 0.129 & 0.218 & 0.308 & 0.002 & 0.007 & 0.022 & 0.081 & 0.157 & 0.251 & 0.001 & 0.005 & 0.018 \\
\hline$\left(\mathrm{I}_{2-3}\right)$ & 0.074 & 0.26 & 0.462 & 0.001 & 0.006 & 0.028 & 0.024 & 0.123 & 0.239 & 0.000 & 0.003 & 0.015 \\
\hline$\left(\mathrm{I}_{2-4}\right)$ & 0.032 & 0.271 & 0.62 & 0.000 & 0.006 & 0.038 & 0.008 & 0.115 & 0.298 & 0.000 & 0.003 & 0.018 \\
\hline$\left(\mathrm{I}_{3}\right)$ & 0.162 & 0.225 & 0.35 & 0.005 & 0.011 & 0.032 & 0.121 & 0.183 & 0.298 & 0.003 & 0.009 & 0.027 \\
\hline$\left(\mathrm{I}_{4}\right)$ & 0.085 & 0.172 & 0.344 & 0.003 & 0.012 & 0.047 & 0.139 & 0.269 & 0.46 & 0.005 & 0.019 & 0.063 \\
\hline$\left(I_{5}\right)$ & 0.11 & 0.183 & 0.287 & 0.003 & 0.011 & 0.039 & 0.144 & 0.202 & 0.307 & 0.004 & 0.013 & 0.042 \\
\hline$\left(I_{6}\right)$ & 0.099 & 0.209 & 0.344 & 0.002 & 0.010 & 0.034 & 0.081 & 0.166 & 0.299 & 0.002 & 0.008 & 0.030 \\
\hline$\left(\mathrm{I}_{7}\right)$ & 0.111 & 0.196 & 0.326 & 0.003 & 0.010 & 0.035 & 0.149 & 0.242 & 0.383 & 0.004 & 0.012 & 0.041 \\
\hline$\left(\mathrm{I}_{8}\right)$ & 0.11 & 0.187 & 0.311 & 0.004 & 0.013 & 0.043 & 0.147 & 0.232 & 0.362 & 0.005 & 0.016 & 0.050 \\
\hline$\left(\mathrm{I}_{9}\right)$ & 0.084 & 0.171 & 0.317 & 0.003 & 0.012 & 0.043 & 0.135 & 0.238 & 0.389 & 0.004 & 0.016 & 0.053 \\
\hline$\left(\mathrm{I}_{10}\right)$ & 0.099 & 0.209 & 0.344 & 0.004 & 0.017 & 0.052 & 0.099 & 0.209 & 0.344 & 0.004 & 0.017 & 0.052 \\
\hline$\left(\mathrm{I}_{11}\right)$ & 0.123 & 0.23 & 0.328 & 0.004 & 0.014 & 0.035 & 0.071 & 0.128 & 0.195 & 0.002 & 0.008 & 0.021 \\
\hline$\left(\mathrm{I}_{12-1}\right)$ & 0.093 & 0.186 & 0.352 & 0.001 & 0.004 & 0.019 & 0.114 & 0.234 & 0.405 & 0.001 & 0.005 & 0.022 \\
\hline$\left(\mathrm{I}_{12-2}\right)$ & 0.093 & 0.181 & 0.334 & 0.001 & 0.003 & 0.014 & 0.114 & 0.228 & 0.384 & 0.001 & 0.004 & 0.016 \\
\hline$\left(\mathrm{I}_{12-3}\right)$ & 0.103 & 0.191 & 0.332 & 0.001 & 0.005 & 0.023 & 0.138 & 0.235 & 0.39 & 0.001 & 0.007 & 0.027 \\
\hline$\left(\mathrm{I}_{13}\right)$ & 0.103 & 0.21 & 0.345 & 0.003 & 0.010 & 0.030 & 0.135 & 0.231 & 0.369 & 0.004 & 0.011 & 0.032 \\
\hline$\left(\mathrm{I}_{14}\right)$ & 0.148 & 0.207 & 0.312 & 0.003 & 0.006 & 0.015 & 0.11 & 0.169 & 0.266 & 0.002 & 0.005 & 0.013 \\
\hline$\left(\mathrm{I}_{15}\right)$ & 0.105 & 0.213 & 0.382 & 0.001 & 0.004 & 0.013 & 0.081 & 0.147 & 0.264 & 0.001 & 0.003 & 0.009 \\
\hline$\left(\mathrm{I}_{16}\right)$ & 0.099 & 0.201 & 0.312 & 0.001 & 0.005 & 0.012 & 0.081 & 0.16 & 0.272 & 0.001 & 0.004 & 0.011 \\
\hline$\left(\mathrm{I}_{17}\right)$ & 0.094 & 0.194 & 0.308 & 0.002 & 0.006 & 0.018 & 0.124 & 0.214 & 0.329 & 0.002 & 0.007 & 0.020 \\
\hline (18) & 0.104 & 0.217 & 0.371 & 0.002 & 0.007 & 0.022 & 0.081 & 0.15 & 0.256 & 0.002 & 0.005 & 0.015 \\
\hline \multicolumn{4}{|c|}{ Final priorities } & 0.053 & 0.202 & 0.661 & & & & 0.058 & 0.218 & 0.690 \\
\hline
\end{tabular}


Selection of the optimum WWTP by AHP

Table 7: Estimation of alternatives crisp priorities

\begin{tabular}{|c|c|c|c|c|c|c|}
\hline \multirow{2}{*}{ Treatment process } & \multicolumn{3}{|c|}{ Final priorities } & \multirow{2}{*}{$\begin{array}{l}\text { Weight } \\
\text { vector }\end{array}$} & \multirow{2}{*}{$\begin{array}{l}\text { Overall } \\
\text { priority }\end{array}$} & \multirow{2}{*}{$\begin{array}{l}\text { Rank } \\
\text { order }\end{array}$} \\
\hline & l & $\mathrm{m}$ & $\mathrm{u}$ & & & \\
\hline Extended aeration & 0.056 & 0.212 & 0.68 & 0.316 & 0.206 & 2nd \\
\hline $\mathrm{A} / \mathrm{B}$ & 0.048 & 0.187 & 0.63 & 0.288 & 0.188 & 5th \\
\hline IFAS & 0.058 & 0.218 & 0.69 & 0.322 & 0.210 & 1 st \\
\hline SBR & 0.053 & 0.202 & 0.661 & 0.305 & 0.199 & 3rd \\
\hline Aerated lagoon & 0.055 & 0.2 & 0.643 & 0.299 & 0.196 & 4th \\
\hline
\end{tabular}

the rest of the process. In the next step, membership functions are constructed for the each criterion and intersections are determined by comparing each couple. In the fuzzy logic approach, for each comparison the intersection point is found, and then the membership values of the point correspond to the weight of that point. This membership value can be also defined as the degree of possibility of the value. For a particular criterion, the minimum degree of possibility of the situations, in which the value is greater than the others, is also the weight of this criterion before normalization. After obtaining the weights for each criterion, they are normalized and called the final importance degrees or weights for the hierarchy level.

In the decision-making process, the fuzzy comparison judgment matrices are decided according to the suggestions of the wastewater specialists. The imprecise and uncertain assessments of them are translated into corresponding triangular fuzzy numbers according to Table 4.

The evaluations are expressed using the fuzzy scale of preferences (see Table 4) and then the composite relative priorities are calculated as illustrated in Table 5. Finally, the alternatives are compared according to their performance in each one of the selection criteria using scales for the quantitative parameters, and AHP scale of weights for the qualitative criteria.

According to Eq. 3, the fuzzy impact of alternatives is obtained by adding the synthetic degrees values $S_{i}$ weight by the corresponding fuzzy composite relative priorities of the parent node criterion (see Table 6). Then, the final ranking is estimated using Eq. 2. The final ranking of alternatives based on the fuzzy AHP is illustrated in Table 7.

The ranking order of the alternatives with the fuzzy AHP method is as follows: IFAS $>$ Extended Aeration $>$ SBR $>$ Aerated Lagoon $>$ A/B. The comparison of the ranking order of alternatives in this method is approximately similar to the AHP method, only the order of SBR and Aerated Lagoon are changed to each other.

\section{CONCLUSION}

Selection of the wastewater treatment process is a complicated multi-criteria decision making process, which uncertainty, complexity and hierarchy are the most important in terms of its characteristics. In this paper, a practical approach is presented for selecting and weighing the wastewater treatment process problem based on the AHP and fuzzy AHP methods. The decision criteria were technical/administrative, economical and environmental criteria as well as their sub-criteria. These criteria were evaluated to determine the order of aerobic alternatives for selecting the most appropriate one. The aerobic alternatives include extended aeration, absorption bio-oxidation (A/B), integrated fixed-film activated sludge (IFAS), sequencing batch reactor (SBR) and aerated lagoon. By using the AHP method, the ranking order of the alternatives was as follows: IFAS $>$ Extended Aeration $>$ Aerated Lagoon $>$ SBR $>$ A/B. The sensitivity analysis for the criteria level showed that the ranking order of alternatives remained constant with changing the value of main three criteria. According to the fuzzy AHP, the best alternative was IFAS and the ranking order of the alternatives was as follows: IFAS > Extended Aeration $>$ SBR $>$ Aerated Lagoon $>$ A/B. The comparison of the ranking order of alternatives in this method was approximately similar to the AHP method, only the order of SBR and aerated lagoon were changed to each other. So, when the sensitivity analysis was done with respect to main criteria, less changes has occurred to ranking of alternatives.

The application of this approach to the real case shows that the AHP method is easy to use and understand by the experts. Application of both AHP and fuzzy AHP methods for the complex problem of selection of the wastewater treatment process has done 
in this study for the first time. With regard to dealing with many criteria in a problem, it is better to use the AHP method and apply the expert choice (EC) software to simplify calculation; however, the fuzzy AHP method is preferred when the criteria weights and performance ratings are vague and inaccurate. An appropriate decision making method should be taken into account according to the situation and the structure of the problem. In future studies, other multiple criteria methods, such as fuzzy TOPSIS and ELECTRE can be used for the selection of the wastewater treatment process.

\section{ACKNOWLEDGEMENTS}

The authors would like to thank Iran Small Industries and Industrial Estates Organization for the partially financial support for the research project entitled "Comprehensive investigation of wastewater treatment plant which is operating in Iran industrial estates and appropriate treatment process selection” (No. D/2222).

\section{REFERENCES}

Anagnostopoulos, K. P.; Gratziou, M.; Vavatsikos, A. P., (2007). Using the fuzzy hierarchy process for selecting wastewater facilities at prefecture level. Eur. Water, 19 (20), 15-24 (10 pages).

Badri, M. A., (1999). Combining the analytic hierarchy process and goal programming for global facility location-allocation problem. Int. J. Prod. Econ., 62 (3), 237-248 (12 pages).

Bandyopadhyay, G.; Chattopadhyay, S., (2007). Single hidden layer artificial neural network models versus multiple linear regression model in forecasting the time series of total ozone. Int. J. Environ. Sci. Tech., 4 (1), 141-150 (10 pages).

Bouyssou, D.; Marchant, T.; Pirlot, M.; Perny, P.; Tsoukias, A.; Vincke, P., (2000). Evaluation and decision Models: A critical perspective. Kluwer Academic Publishers, Boston.

Chang, D. Y., (1996). Applications of the extent analysis method on fuzzy AHP. Eur. J. Oper. Res., 95 (3), 649-655 (7 pages)

Chen, M. F.; Tzeng, G. H.; Ding, C. G., (2008). Combining fuzzy AHP with MDS in identifying the preference similarity of alternatives. Appl. Soft Comput., 8 (1), 110-117 (8 pages).

Cheng, S.; Wang, R., (2004). Analyzing hazard potential of typhoon damage by applying grey analytic hierarchy process. Nat. Hazard., 33 (1), 77-103 (27 pages).

Chien, M. K.; Shih, L. H., (2007). An empirical study of the implementation of green supply chain management practices in the electrical and electronic industry and their relation to organizational performances. Int. J. Environ. Sci. Tech., 4 (3), 383-394 (12 pages).

Dabaghian, M. R.; Hashemi, S. H.; Ebadi, T.; Maknoon, R., (2008). The best available technology for small electroplating plants applying analytical hierarchy process. Int. J. Environ. Sci. Tech., 5 (4), 479-484 (6 pages).
Dikinya, O.; Areola, O., (2010). Comparative analysis of heavy metal concentration in secondary treated wastewater irrigated soils cultivated by different crops. Int. J. Environ. Sci. Tech., 7 (2), 337-346 (10 pages).

Ellis, K. V.; Tang, S. L., (1991). Wastewater treatment optimization model for developing world. I: Model development. J. Environ. Eng. Div., ASCE 117 (4), 501518 (18 pages).

Ellis, K. V.; Tang, S. L., (1994). Wastewater treatment optimization model for development world. II: Model testing. J. Environ. Eng. Div., ASCE, 120 (3), 610-624 (15 pages).

Enea, M.; Piazza, T., (2004). Project selection by constrained fuzzy AHP. Fuzz. Optim. Decis. Ma., 3 (1), 39-62 (24 pages).

Expert Choice, Inc., (2000). Expert Choice software and manual. 4922 Els worth Ave., Pittsburgh, PA 15213, USA.

Guangming, Z.; Jiang, R.; Huang, G.; Xu, M.; Li, J., (2007). Optimization of wastewater treatment alternative selection by hierarchy grey relational analysis. J. Environ. Manag., 82 (2), 250-259 (10 pages).

Hadji Hosseinlou, M.; Sohrabi, M., (2009). Predicting and identifying traffic hot spots applying neuro-fuzzy systems in intercity roads. Int. J. Environ. Sci. Tech., 6 (2), 309314 (6 pages).

Hsich, T. Y.; Lu, S. T.; Tzeng, G. H., (2004). Fuzzy MCDM approach for planning and design tenders selection in public office buildings. Int. J. Proj. Manag., 22 (7), 573-584 (12 pages).

Isiklar, G.; Buyukozkan, G., (2006). Using a multi-criteria decision making approach to evaluate mobile phone alternatives. Comp. Stand. Inter., 29, 265-274 (10 pages).

Khezri, S. M.; Lotfi, F.; Tabibian, S.; Erfani, Z., (2010). Application of water pinch technology for water and wastewater minimization in aluminum anodizing industries. Int. J. Environ. Sci. Tech., 7 (2), 281-290 (10 pages).

Klir, G. J., (1997). Fuzzy arithmetic with requisite constraints. Fuzzy Set. Sys., 91 (2), 165-175 (11 pages).

Kulak, O.; Kahraman, C., (2005). Fuzzy multi-attribute selection among transportation companies using axiomatic design and Analytic Hierarchy Process. Inform. Sci., 170 $(2,4), 191-210$ (20 pages).

Lamata, M. T., (2004). Ranking of alternatives with ordered weighted averaging operators. Int. J. Intell. Syst., 19 (5), 473-482 (10 pages).

Leung, L. C.; Chao, D., (2000). On consistency and ranking of alternatives in Fuzzy AHP. Eur. J. Oper. Res., 124, 102-113 (12 pages).

Liang, G. S., (1999). Fuzzy MCDM based on ideal and anti-ideal concepts. Eur. J. Oper. Res., 112 (3), 682-691 (10 pages).

Metcalf and Eddy, (2003). Wastewater engineering: treatment, disposal, reuse. $4^{\text {th }}$ Ed., Tata McGraw-Hill Co., New Delhi.

Nouri, J.; Karbassi, A. R.; Mirkia, S., (2008). Environmental management of coastal regions in the Caspian Sea. Int. J. Environ. Sci. Tech., 5 (1), 43-52 (10 pages).

Panjeshahi, M. H.; Ataei, A., (2008). Application of an environmentally optimum cooling water system design in water and energy conservation. Int. J. Environ. Sci. Tech., 5 (2), 251-262 (12 pages).

Saaty, T. L., (1977). A scaling method for priorities in hierarchical structures. J. Math. Psychol., 15 (3), 234-281 (58 pages). 
Saaty, T. L., (1988). The analytic hierarchy process: Planning, priority setting, resource allocation. Pittsburgh, PA: RWS Publications.

Saaty, T. L., (1990). How to make a decision: The analytic hierarchy process. Eur. J. Oper. Res., North-Holland, 48 (1), 9-26 (18 pages)

Saaty, T. L., (2001). Decision Making for Leaders: The Analytic Hierarchy Process for Decisions in a Complex World, New Ed. Analytic Hierarchy Process Series, Vol. 2.

Soner Kara, S.; Onut, S., (2010). A stochastic optimization approach for paper recycling reverse logistics network design under uncertainty. Int. J. Environ. Sci. Tech., 7 (4), 717-730 (14 pages).

Taha, H. A., (2003). Operations research: An introduction. $9^{\text {th }}$ Ed., Pearson Education Inc.

Taylor, B. W., (2009). Introduction to Management Science: Global Ed., Pearson Education Inc.

Tuzkaya, G.; Gülsün, B., (2008). Evaluating centralized return centers in a reverse logistics network: An integrated fuzzy multi-criteria decision approach. Int. J. Environ. Sci. Tech., 5 (3), 339-352 (14 Pages).
Tuzkaya, G.; Ozgen, A.; Ozgen, D.; Tuzkaya, U. R., (2009). Environmental performance evaluation of suppliers: A hybrid fuzzy multi-criteria decision approach. Int. J. Environ. Sci. Tech., 6 (3), 477-490 (14 pages).

Tuzkaya, U. R., (2009). Evaluating the environmental effects of transportation modes using an integrated methodology and an application. Int. J. Environ. Sci. Tech., 6 (2), $277-$ 290 (14 pages).

Van Laarhoven, P. J. M.; Pedrycz, W., (1983). A fuzzy extension of Saaty's priority theory. Fuzz. Set. Sys., 11 (1-3), 199-227 (28 pages).

Vargas, L. G., (1982). Reciprocal matrices with random coefficients. J. Math. Model., 3 (1), 69-81 (13 pages).

Zhao, X.; Shen, Z.; Xiong, M.; Qi, J., (2011). Key uncertainty sources analysis of water quality model using the first order error method. Int. J. Environ. Sci. Tech., 8 (1), 137-148 (12 pages).

Zhu, K. J.; Jing, Y.; Chang, D. Y., (1999). A discussion on extent analyses method and applications of fuzzy AHP. Eur. J. Oper. Res., 116 (1), 450-456 (7 pages).

\author{
AUTHOR (S) BIOSKETCHES \\ Karimi, A. R., Ph.D. Student of Environmental Engineering, Faculty of Environment, University of Tehran, Tehran, Iran. \\ Email: karimia@ut.ac.ir \\ Mehrdadi, N., Ph.D., Associate Professor, Faculty of the Environment, University of Tehran, Tehran, Iran. Email: mehrdadi@ut.ac.ir \\ Hashemian, S. J., Associate Professor, Institute of Water and Energy, Sharif University of Technology, Tehran, Iran. Email: jamal@sharif.edu \\ Nabi Bidhendi, G. R., Professor, Faculty of the Environment, University of Tehran, Tehran, Iran. Email: ghhendi@ut.ac.ir \\ Tavakkoli Moghaddam, R. Professor, Department of Industrial Engineering, University of Tehran, Tehran, Iran. Email: tavakoli@ut.ac.ir
}

How to cite this article: (Harvard style)

Karimi, A. R.; Mehrdadi, N.; Hashemian, S. J.; Nabi Bidhendi, G. R.; Tvakkoli-Moghaddam R., (2011). Selection of wastewater treatment process based on the analytical hierarchy process and fuzzy analytical hierarchy process methods. Int. J. Environ. Sci. Tech., 8 (2), 267-280. 